\title{
La subversión de la
}

\section{ausencia. Reseña a La}

\section{trama teórica. Escritos}

\section{de teoría literaria y}

\section{literatura comparada,}

de Javier Morales

Mena (comp.)

Douglas Rubio Bautista

tchudrub@upc.edu.pe Universidad Peruana de Ciencias Aplicadas

Resumen: El autor reseña la compilación La trama teórica. Escritos de teoría literaria y literatura comparada de Javier Morales Mena. Este texto reúne nueve artículos en donde se discuten el territorio epistemológico de los estudios literarios, la necesidad de un debate y un replanteamiento al margen del canon y de la tradición ortodoxa. Así La trama teórica..., revisa los lazos construidos entre la teoría y la literatura comparada.

Palabras clave: Literatura comparada, teoría literaria, tradición, canon, estudios literarios

Abstract: The author reviews the compilation La trama teórica. Escritos de teoría literaria y literatura comparada by Javier Morales Mena. This text brings together nine articles where the epistemological territory of literary studies are discussed, the need for a debate and a rethinking outside of the canon and the Orthodox tradition. Therefore, La trama teórica...goes through the links built between theory and comparative literature. 
Keywords: Comparative literature, literary theory, tradition, canon, literary studies

$$
\mathrm{L}
$$
a compilación de Javier Morales Mena está regido por dos coordenadas centrales en su corpus: la subversión y, en giro freudiano, el «retorno de lo reprimido». El espíritu de cada artículo seleccionado (nueve en total) desarrolla la vertiente de la denuncia y el reclamo a partir de discutir el territorio epistemológico de los estudios literarios debatirlo y replantearlo al margen del canon y la tradición ortodoxa-, e institucionalizar al componente excluido como estancia de sus reflexiones: lo no-dicho, lo marginado, lo silenciado. Esa «oveja perdida» reclamada por Asensi. Así, el tema de La trama teórica..., revisa los lazos construidos entre la teoría y la literatura comparada bajo un contexto de subversión radical de ambas esferas cognitivas, siendo cuatro sus principios organizadores: a) reconfiguración del campo teórico hoy; b) análisis de sus fundamentos epistemológicos; c) recorrido por la transformación metafórica y tropológica de categorías teóricas y, finalmente, proporción importante, d. el rol de la ideología y la axiología, de la política y la ética, como sus estatutos centrales. Bajo estos principios, como andamiaje teórico, la deconstrucción, la fenomenología, a la vez del estatuto político de los estudios culturales.

En el primer artículo, «El conflicto del canon y la teoría literaria: una retórica de la crisis», la revisita a la teoría literaria y la Literatura comparada, su huella evolutiva, concluye actualmente en un balance convulso en opinión de José María Pozuelo. Sin embargo, frente a la doxa apocalíptica, el crítico español rescata el viento favorable con respecto a esto que denomina «la retórica de la crisis» (sintagma «crisis de las Humanidades», puerta abierta que cuestiona sus fundamentos: ¿qué es la literatura? y ¿qué literatura se enseña?). Así, la valoración de este fenómeno permite a la teoría literaria debatir no solo sus estatutos más íntimos, cercanos, sino de incluirse en discusiones que alcanzan a la crítica cultural, apostar por lecturas ideológicas y observarse como lugar heterogéneo. Un escenario que Pozuelo organiza a partir de dos fronteras epistemológicas muy vinculadas: el cambio de su objeto de estudio y el de su lugar de enseñanza (es decir, cuál es el terreno propio de la teoría literaria y dónde se desarrollan sus principales polémicas), y que permite observar dos problemas fundamentales para la teoría literaria actual: asumir el caos y crisis constante de la teoría literaria y al debate de lo que se ha llamado «crítica de la razón política». En el caso primero, la acción de la teoría no se instala bajo el reducto propio del texto literario. Hoy, la teoría ya 
no discute solo desde la hermenéutica, sino que observa y cuestiona su propia naturaleza y la de los sujetos que la estudian; motivo para que Pozuelo incorpore el factor ideológico y ético en el rol de este llamado «sujeto de la teoría», a la vez de denunciar el fin de la inocencia, pues el lugar desde donde se ubica el objeto literario es efecto de este sujeto y el campo político y epistemológico que lo configura. El segundo escenario de la crisis, la pedagógica, continuidad de la anterior, ratifica a este panorama teórico como objeto de pugna y de poder y control institucional. La crisis parte desde la institución literaria norteamericana frente a las posiciones resistentes (los estudios culturales, por ejemplo), quienes cuestionan cualquier noción impositiva canónica de cultura y de literatura. Así, Pozuelo plantea el desafío de la teoría hoy tras aceptar que jamás ha existido una estabilidad o natural de la teoría. El fundamento de la teoría, aclara, no es encontrar resolver la crisis, sino la de develar este caos constante y aprender a convivir con el mismo.

Si Pozuelo reclama a la teoría literaria como espacio heterogéneo y de caos perpetuo, Javier Morales Mena, en «La teoría literaria y la transformación de sus metáforas conceptuales», el segundo artículo, aguza esta lectura, secundado por la deconstrucción y el proyecto hermeneuta de Gadamer, al advertir una vía paradójica en su constitución discursiva contemporánea y observa, sobre todo, un lugar subjetivo, inasible a lo racional en su objeto de estudio. Ciencia incapaz de reducirlo, dominarlo y racionalizarlo. Con una fuerte impronta filosófica, para J. Morales, la teoría, si bien asume el ideal verista y objetivo de las ciencias fácticas, también adquiere un margen que elude lo reduccionista positivista de la lógica racional y se implica, más bien, con su propio objeto de estudio, al punto de reconocerla ambigua e indecidible. De estimar a lo literario como su «otro constitutivo» y no un objeto externo al mismo. A esta última consideración la denomina theoría, o la teoría literaria como género de escritura.

El artículo se organiza sobre dos apartados principales. En el primero, Morales observa a la teoría literaria como ciencia idealizadora de programas y métodos de la teoría científica. La reflexión, en todo caso, no desestima esta pretensión, aunque advierte sus riesgos, sobre todo por la ortodoxia brindada por su representante notorio: la lingüística, y sus disciplinas estructurales (narratología, semiótica y pragmática), cuyos modelos no necesitan —aparentemente- de ingredientes éticos o ideológicos para explicar su objeto de estudio, y se rige sobre el determinismo, la manipulación y la jerarquización violenta. Como Pozuelo, Morales es contrario a estos actos impositivos. «La teoría moderna está muy vinculada a la técnica y a la manipulación», afirma (Cfr. Morales 2011: 43), en paráfrasis 
a Asensi. En el segundo apartado, la demanda subversiva es la doctrina del artículo al reconocer a la teoría literaria como género de escritura. Morales inclina su lectura hacia el pensamiento filosófico hermenéutico y deconstructivo, para revisitar a la teoría como discurso que reconoce a su objeto, lo literario, no como ajeno ni externo, sino como constitutivo de sí; con el que dialoga, escucha y se mimetiza. A esta posibilidad, término recuperado de Gadamer, la denomina theoría. A cuenta y riesgo, como lo indica, Morales privilegia la hermenéutica ad infinitum antes que el imperio del sentido jerarca en el texto literario.

Los postulados de Idelber Avelar en «La construcción del canon y la cuestión del valor literario», el artículo siguiente, aunque no principales, habían sido ya observados en los juicios de Pozuelo y Morales, respectivamente. Para abreviar, el encuentro ineludible de la huella ideológica con la teoría literaria. Lo deduce Pozuelo cuando describe el caso del «sujeto de la teoría» (administrador y juez que decide qué es o no literatura, qué obras deben ser interpretadas y por qué no otras) y lo enfatiza Morales cuando denuncia que todo intento determinista de explicar, juzgar y «atrapar» en la trama teórica a lo literario es producto de actos de poder y sojuzgamiento. Epistemología, filosofía, ética e ideología; rutas subversivas que Avelar estima ahora desde la axiología. ¿La valoración está separada de la crítica literaria? ¿El gusto es pieza de la teoría literaria o fenómeno del cual debe desprenderse? Para Avelar, en respuesta a las aporías del New Criticism, si es la crítica la organizadora del canon, la axiología es el fundamento de su construcción. Todo ejercicio crítico cientifico, a la vez del rigor y pretensión objetiva, asevera Avelar, se caracteriza, en última instancia, por su pulsión ética. Para justificarla, recurre a la noción de "extrañamiento» del formalismo ruso y cómo sus "gustos» y juicios de valor se relativizan hacia aquella literatura cuya representación desarrolle o no esta categoría. Por cierto, la pretensión de Avelar no está en definir valores estéticos universales ni menos defenderlos; más bien, caracteriza su emergencia pulsional como producto de interacciones y conflictos sociales. A su vez, citando a B. Herrnstein Smith, asume al valor como siempre y necesariamente contingente. Es decir, ¿qué se debe apreciar en la literatura? ¿Cuál es su virtud? Nada hay pret a porter. Más bien, un valor se realiza, depende, se objetiva y motiva, en el interior de una comunidad y su eficacia la volvería, solo en apariencia, no-contingente.

Los estudios de literatura comparada, según Manuel Asensi en «La oveja perdida y la emancipación de la literatura comparada», han renovado el panorama de la teoría literaria al reconocer que no basta el fenómeno literario como objeto de estudio para entender 
la literatura, sino que necesita incorporar las prácticas artísticas habidas y los campos del saber para su interpretación. Si los artículos anteriores describen los riesgos de cualquier pretensión reduccionista con respecto a los fundamentos de lo literario, Asensi desarrolla esta línea en el territorio de la práctica hermenéutica de la comparada, aunque advierte de un marco teórico que incorpore su proyecto discursivo. Expliquemos: el español expone su tesis a partir de estos principios: La expansión del campo de estudio de la comparada es debido a la «esponjosidad» del texto literario. Es decir, todo texto literario tiene capacidad de penetrar a otro (sea este un texto literario, una canción, una película, una pintura, una red social, una idea filosófica, etc.) y viceversa. Es una cualidad universal del texto. Fundamentado en la categoría derridiana de «heterogeneidad» (la comprensión de un texto solo es posible a partir de otros) y en la noción de "paragrama» de Julia Kristeva (el sentido del texto literario se comprende dentro del universo de textos y es una respuesta a otros textos), principalmente, Asensi señala que la comparada debe tomar en cuenta dos coordenadas: el sentido del texto se sostiene en su conexión intertextual y la teoría literaria debe incorporar este registro a sus estudios. Fundamentalmente, el estudio de la comparada es empírico. Su registro se revela en la crítica y la hermenéutica particular del texto; aun así, su práctica modifica también a la teoría, pues "proporciona un contenido empírico lo suficientemente extenso como para provocar modificaciones y cambios en los modelos teóricos que sustentan el acercamiento a los textos literarios» (Cfr. Morales 2011: 87). En esta estancia, Asensi concluye: la literatura comparada debe ser definida bajo esta condición, a la que llama "poética relacional", y su objetivo debe ser el análisis del elemento relacional del texto literario. Finalmente, en continuidad con la pretensión de atender al componente que ha sido excluido o silenciado de los estudios de la teoría literaria, predicado por Pozuelo y Morales, y cómo esta refiere a imposiciones de carácter ideológicas y axiológicas (como lo sostiene Avelar), Asensi reclama la presencia de la ausencia; es decir, huyendo del canon occidental tradicional, la literatura comparada debe persistir en incorporar a sus estudios lenguas y literaturas, discursos y semióticas, no previstas ni contempladas por el canon comparatista instalada por la ortodoxia. La intertextualidad no solo se debe realizar con las relaciones previstas, sino con aquellos que, en apariencia, no tendría un lazo de sentido. Como en la parábola cristiana, debe atender a esa «oveja descarriada» y preguntarse por las razones de su ausencia.

El factor «ausente» reincide en el artículo de Alberto Moreiras, «Literatura infrapolítica: hispanismo y frontera». Si bien su obsesión interrogante se determina sobre dos estancias, fundamentos, de la propuesta conjunta de La trama...::por qué literatura?, 
y ¿por qué reflexión sobre la literatura?, ambas respuestas las elabora, sobre todo, con el recurso fenomenólogico y, en menor intensidad, pulsional diría, bajo la disciplina freudiana. Para este escenario, Moreiras recupera, sin ser suya exclusiva, la noción de lo «infrapolítico», dimensión presente no solo en el pensamiento literario, sino en la cultura en general y, en especial, en el «hispanismo», historia y práctica reflexiva sobre los pueblos y culturas marcados por la lengua castellana que, tras la intervención de la dimensión aludida como categoría general, se subvierte a prácticas democráticas. La comprensión de lo infrapolítico es, según Moreiras, aceptar la condición de que en las prácticas culturales, y por ende en la literatura, su esfera de acción no es solo política (sujetos inmersos en relaciones de poder); menos aún ética. ¿Qué significa, entonces, la práctica literaria desde el terreno de la experiencia infrapolítica? Si el hispanismo es su dimensión infrapolítica (aunque luego asume que esa frontera debe desdibujarse hacia la expansión), la literatura debe recuperar, volver hacia, aquel espacio inasible, trascendente, fenomenología que busca la esencia del objeto; en otras palabra, pensar «el fondo oscuro»: la experiencia olvidada que originó el texto, nuestra narración; aquello reprimido incapaz de retornar siempre que el sujeto no se distancie de la representación canónica occidental y, sobre todo, no apele a la memoria para recordar lo olvidado de la experiencia: «Hay algo más, hay siempre algo más, de lo que el aparato representacional científico filosófico no puede hacerse cargo», dice Moreiras (Cfr. Morales 2011:100).

En lectura de Levinas, este retorno no es posible sin la «objetificación» de la experiencia concreta; es decir, es necesaria la textura (la realidad, la manifestación cultural) para ir internándose en el espacio de la esencia, o aquello que Lacan denominaría «lo real». A este fenómeno, Moreiras la denomina «experiencia infrapolítica» y la vincula a esa literatura cuyo estatuto de ficción tiene como propósito último la autorrevelación y la autoexposición. No hay un impulso politico o ético totalizador, a la manera de Kant: solo la necesidad de querer exponernos; de exponernos a otros, sin cálculos, interés ni patologias: a eso denomina "literatura infrapolítica». Penitencia que, por cierto, podría responder a las dos estancias, en principio señaladas, pues el acceso a la vida sin textura es imposible (¿esa eterna búsqueda de la experiencia olvidada se detendría en algún momento?, ¿ese trauma imposible por fin se podrá simbolizar?): «El misterio es que no hay misterio», lo que fuerza al sujeto a continuar su imposible, y apasionada, búsqueda. Esto descubre a la literatura como pensamiento de fondo oscuro (insistir en volver a lo reprimido), y espacio donde el sujeto se autoexpone 
radicalmente y se realiza, a medida que porfía recuperar aquello perdido e irrecuperable, pero constitutivo de sí.

Los siguientes artículos, de Dolores Romero y Genara Pulido, respectivamente, piensan la teoría literaria no solo como dinámica actual frente a nuevos escenarios, sino como disciplina que recupera reflexiones cuya presencia aún es pertinente. En el caso de Romero, su artículo: «La literatura comparada ante la crisis de las humanidades: hacia una teoría de la lectura digital», observa cómo los nuevos espacios digitales no solo han replanteado la dinámica cultural y las identidades en el mundo hoy, sino ha modificado el significado de lo que se entiende por los estudios literarios; en específico: literatura comparada, Poética y Teoría. La comprensión de este movimiento actual, tiene en la noción de «hipertexto» y "globalización», factores claves para introducirse en este tránsito. En otras palabras, el texto literario considera, hoy, distintas formas de soporte, más allá de la convencional hoja de papel, tras su digitalización; por ello, en el caso de la dinámica global, el texto literario, digitalizado, se vuelve en emisor-creador global para un receptor-lector global, también. Un nuevo cambio paradigmático que, como se observa, responde a una crisis que Romero identifica en dos áreas específicas: a. crisis de la Lectura; y b. crisis de la Textualidad. Es decir, ¿cómo se debe leer e interpretar ahora una obra literaria a la luz de lo digital y lo global? Romero advierte que todo cambio de paradigma en el espacio de los estudios literarios necesita -como lo fue el discurso de la Retórica, la Estilistica, o el rol del Estructuralismo- una Teoría capaz de asumir posición crítica respecto al nuevo escenario. En el caso hoy, una Teoría de la Lectura Digital que revise y defina lo que se entiende por literatura digital (¿un nuevo género literario?, ¿solo una forma novedosa de escribir literatura?). Sin rendirse a versiones apocalípticas, este modo de «hipertexto» (o «texto compuesto por fragmentos de textos y por los enlaces electrónicos que los conectan entre sí») es, para Romero, una dinámica de la literatura digital que recoge de la teoría posmoderna los fundamentos necesarios para su reconocimiento positivo. De otro lado, tras la revisión teórica del fenómeno, Romero vuelve a Latinoamérica y reflexiona sobre los alcances y el replanteamiento de la literatura digital, su narrativa, en perspectiva de los estudios culturales y cómo se instala el debate de lo que es «nación» e «identidad» a partir del mundo digital globalizado, además de analizar la praxis literaria sobre esta tecnología a partir de escritores nativos. Luego, en el caso de Pulido: «El estudio de los temas en la literatura comparada. Algunas cuestiones teóricas fundamentales», los nuevos campos del saber de los estudios literarios no inciden solo en el universo de la posmodernidad y la tecnología digital. Su sustancia o núcleo, se ubica, 
a su vez, en recuperar y revalorar estudios que, en su momento, resultaron bastardeados. En el caso concreto del estudio de los temas en la literatura (desarrollado en el marco historicista del siglo XIX), o tematología, y su rechazo en el siglo XX por el pretensioso discurso metateórico, estructural y autónomo, que la asume rudimentaria e insuficiente para describir el objeto literario, Pulido la ubica, más bien, como central en el pensamiento crítico de la literatura comparada y en la teoría literaria, dada la lectura y revitalización de las tendencias críticas como lo poscolonial y los estudios culturales: su estancia recupera y piensa al tema como punto de encuentro entre la realidad extratextual, el discurso literario y la cultura.

El artículo de Darío Villanueva Prieto, «La transformación de la obra literaria: los Macbeth de Roman Polanski y de Harold Bloom», si bien es un ejercicio plenamente hermenéutico, el diálogo entre dos textos productos del clásico shakespeareiano, es, a su vez, un acercamiento a la revalidación de prácticas semióticas no tomadas en cuenta por la teoría literaria y, tan importante, una denuncia a la subestimación del sétimo arte, práctica discursiva que debiera ser puesta en crítica y atendida como fenómeno representacional autónomo. El desarrollo de su propuesta atiende a una red teórica fundada en el concepto heterogéneo y articulador de "Literatura como Sistema», de Claudio Guillén; coordenada semiótica que determina a la Literatura en un contexto básico de acciones comunicativas (y por tanto, sociales), a saber: a. la producción de textos; b. la mediación para su difusión; c. la recepción de público lector y d. el posprocesado, factor clave de este circuito, pues significa la «recreación» del texto literario; en buen romance, su «transducción», que representa la inserción de un texto en otro texto hasta la transformación del género originario en una obra diferentes. Para Villanueva, actividades como la paráfrasis crítica y la traducción, y especialmente la transducción fílmica (es decir, «adaptar» un texto literario al lenguaje cinematográfico;) son fenómenos constantes en la realización de la semiótica de la comunicación literaria, cuyo análisis debe ser incorporado y revisado por los estudios literarios actuales, más aún si Genette ya había denominado a estas operaciones como «transformación» (cuando un texto B o «hipertexto» se deriva de uno anterior, texto A o «hipotexto»).

Finalmente, Javier Morales Mena en «Los estudios de literatura comparada en el Perú actual» elabora una cartografía incompleta, insuficiente y fragmentaria, pero necesaria, de los estudios últimos de literatura comparada llevados a cabo en el Perú, bajo un solo panorama: concluir la definición de literatura comparada que subyace a cada análisis efectuado en justa comparativa; a la vez de, más importante, reflexionar sobre su propia 
definición. Soporte de esta proyección, es la organización del corpus a analizar bajo tres secciones comparativas: literatura-literatura (comparación intraliteraria); literatura-pintura, literatura-cine (comparación intersemiótica) y literatura con otros discursos no literarios: literatura-filosofía, literatura-ética (comparación interdiscursiva). Al respecto, el articulista no solo ambiciona lo multidisciplinar comparativo, incorpora también diversos periodos políticos sociales a su análisis bajo el ideario de reconstruir los grados ideológicos ocultos en las representaciones observadas. Una propuesta ya delineada por Avelar y Asensi, pendientes de cómo la perspectiva axiología e intertextual puede explicar el sentido del texto tras la instancia comparativa en su discurso. «La comparación puede ser entendida como una actitud intelectual de integración y comprensión de los múltiples —homogéneos y heterogéneos- fenómenos discursivos y culturales», indica. Pensar la literatura, entonces, reclama la distancia de la insularidad y la proximidad de los lazos vinculantes. 